Article

\title{
Surface Characterization and Tribological Performance Analysis of Electric Discharge Machined Duplex Stainless Steel
}

\author{
Timur Rizovich Ablyaz ${ }^{1, *}$, Evgeny Sergeevich Shlykov ${ }^{1}$, Karim Ravilevich Muratov ${ }^{1}$, \\ Amit Mahajan $^{2}\left(\mathbb{D}\right.$, Gurpreet Singh ${ }^{3}{ }^{-}$, Sandeep Devgan ${ }^{2}$ and Sarabjeet Singh Sidhu ${ }^{3}(\mathbb{C}$ \\ 1 Mechanical Engineering Faculty, Perm National Research Polytechnic University, 614000 Perm, Russia; \\ kruspert@mail.ru (E.S.S.); karimur_80@mail.ru (K.R.M.) \\ 2 Mechanical Engineering Department, Khalsa College of Engineering and Technology, Amritsar 143001, India; \\ amitmahajan291@gmail.com (A.M.); devgan.sandeep186@gmail.com (S.D.) \\ 3 Mechanical Engineering Department, Beant College of Engineering and Technology, Gurdaspur 143521, \\ India; singh.gurpreet191@gmail.com (G.S.); sarabjeetsidhu@yahoo.com (S.S.S.) \\ * Correspondence: lowrider11-13-11@mail.ru
}

Received: 22 September 2020; Accepted: 5 October 2020; Published: 7 October 2020

\begin{abstract}
The present article focused on the surface characterization of electric discharge machined duplex stainless steel (DSS-2205) alloy with three variants of electrode material (Graphite, Copper-Tungsten and Tungsten electrodes). Experimentation was executed as per Taguchi L18 orthogonal array to inspect the influence of electric discharge machining (EDM) parameters on the material removal rate and surface roughness. The results revealed that the discharge current (contribution: $45.10 \%$ ), dielectric medium (contribution: $18.24 \%$ ) majorly affects the material removal rate, whereas electrode material (contribution: $38.72 \%$ ), pulse-on-time (contribution: $26.11 \%$ ) were the significant parameters affecting the surface roughness. The machined surface at high spark energy in EDM oil portrayed porosity, oxides formation, and intermetallic compounds. Moreover, a pin-on-disc wear analysis was executed and the machined surface exhibits $70 \%$ superior wear resistance compared to the un-machined sample. The surface thus produced also exhibited improved surface wettability responses. The outcomes depict that EDMed DSS alloy can be considered in the different biomedical and industrial applications.
\end{abstract}

Keywords: material processing; DSS-2205 alloy; electric-discharge machining; surface integrity; wear resistance; surface wettability

\section{Introduction}

Today, electric discharge machining notably established itself for the processing of hard and complicated geometrical contours, which are difficult to fabricate by traditional machining techniques $[1,2]$. This non-traditional machining technique showed its proficiency for the applications in the manufacturing of aerospace products, moulds, dies, etc [3,4]. The process is also recommended to fabricate the bio-implants owing to its favorable results in orthopedic fields [5-7]. The input process parameters namely pulse-on-time, pulse-off-time, current, dielectric medium, spark gap voltage, type of electrode and polarity (negative or positive) play a momentous role in the machining of diverse materials $[8,9]$. The optimum set of these machining performance parameters has promisingly enhanced the material removal rate and efficiently improves the surface properties $[10,11]$.

Razavykia et al. [12] reported that the discharge current, pulse-on-time, electrode material, and voltage significantly influence the MRR and surface quality of Co-Cr-Mo alloy. Similarly, Mahajan and Sidhu [13] concluded that pulse-on-time, discharge current and electrode material 
were the dominant parameters for the improvement of corrosion resistance, wear characteristics and biocompatibility of Co-Cr samples. Furthermore, Philip et al. [14] employed the EDM for Ti6Al4V alloy and compared the tribological characteristics of a machined and unmachined specimen. The results of their study exhibited the improved specific wear rate and coefficient of friction due to the formation of oxides and carbide layers on the machined surface. Besides, Devgan and Sidhu [15] executed electro discharge treatment for investigating the surface wettability and corrosion resistance responses of $\beta$-titanium alloy. Simao et al. [16] scrutinized the impact of EDM process parameters on various responses such as material removal rate (MRR), tool wear rate (TWR) and surface hardness of AISI H13 tool steel. They concluded that the machining performance and surface properties of materials could be enhanced by an appropriate combination of EDM operation parameters. For instance, Singh et al. [17] reported dielectric medium and discharge current as eminent parameters for improved microhardness and wear resistance of stainless steel 316L using electro-discharge treatment. The processing of duplex stainless steel (DSS-2205) was carried out by Pramanic et al. [18]. They reported that input parameters i.e., pulse-on-time, pulse-off-time, and wire tension significantly influence the MRR, surface properties and kerf width. Alshemary et al. [19] reported that pulse-on and pulse-off time significantly influenced the wire-EDMing of DSS alloy. However, Rajmohan et al. [20] investigated the impact of wire EDM process parameters on the DSS-2205 alloy. It was observed that the current and pulse-on-time parameters had a considerable effect on MRR and SR. Rajaram et al. [21] utilized EDM for drilling of small holes (3 mm dia.) on DSS 2205. The experimental outcomes revealed that the input parameter such as current significantly contributed to the MRR of DSS alloy. Recently, Mahajan et al. [22] reported the excellent hemocompatibility and corrosion resistance outcomes of ED machined DSS-2205 alloy.

Along with the conventional tool electrodes, researchers also explored the performance of composite electrodes for the machining of hard to machine materials. Khanra et al. [23] considered a $\mathrm{ZrB}_{2}-\mathrm{Cu}$ composite electrode for machining of mild steel workpiece and reported the improved MRR and diminished TWR as compared to the $\mathrm{Cu}$ tool. Similar findings were observed by Tsai et al. [24] who utilized $\mathrm{Cr} / \mathrm{Cu}$ composite electrode and confirmed the formation of a recast layer on the surface that improved the corrosion resistance. The results also demonstrated higher MRR and lower TWR as compared to other metal electrodes. Grisharin et al. [25] observed the improved wear resistance and machining efficiency when a copper-colloidal graphite composite electrode was used to machine different alloys. However, Teng et al. [26] employed a Cu-Ni composite tool for the processing of polycrystalline diamond specimens and suggested better MRR as well as surface roughness responses as compared to the $\mathrm{Cu}$ electrode.

According to the literature survey, as briefly discussed above, it was observed that various materials had been machined using EDM. However, this technique is not considerably reported yet for the machining of duplex stainless steel (DSS-2205) alloy. DSS-2205 can be used as an alternative for austenitic stainless steel (316L) owing to its enormous applications in industry as well as in the biomedical field. This paper reported the effect of different types of tool materials and dielectric medium on material removal rate, surface roughness, morphology, phase transformation, tribological performance, and surface wettability of the EDMed surface. The first step examined the effect of chosen process parameters on the MRR and SR of machined samples, and statically scrutinizes the significant factors. The next step studied the surface morphology and phase analysis of samples depicting superior results using field emission scanning electron microscopy (FE-SEM), x-ray diffractometer (XRD) and energy dispersive x-ray analysis (EDX) techniques. The DSS alloy is commonly utilized in mining industries, heat exchangers and oil or gas processing industries, where wear characteristics and surface wettability play an important role for long term usage of alloy. Therefore, contact angle measurement and pin-on-disc wear tests were performed and compared with the results with an un-machined sample to investigate the tribological and wettability behavior of the EDMed sample. 


\section{Material and Methods}

\subsection{Tool and Workpiece}

In this research, duplex stainless steel (DSS-2205) in the form of a square plate of $90 \mathrm{~mm}$ with a thickness of $20 \mathrm{~mm}$ was procured from Solitaire Impex, Mumbai, India. The workpiece chemical composition of Fe: 69.93\%; Cr: 22.81\%; Ni: 5.2\%; Mo: 3.05\%; Mn: 1.43\%; Si: 0.5\%; C: 0.028\%; P: 0.03\%; S: $0.02 \%$, and density $7.8 \mathrm{~g} / \mathrm{cm}^{3}$; melting point $1350{ }^{\circ} \mathrm{C}$, thermal conductivity 19.4 at $100{ }^{\circ} \mathrm{C} \cdot \mathrm{W} / \mathrm{mK}$, and electrical resistivity $0.085 \times 10^{-6} \Omega \mathrm{cm}$. Duplex stainless steel consists of chromium as its main content after iron and molybdenum which make greater utility of DSS-2205 alloy in the biomedical domain. The traditional machining processes are inappropriate to handle such hard materials. Therefore, under such circumstances, spark erosion commonly known as EDM employed as an emerging technique for treating such hard materials $[27,28]$.

In this study, three different tool electrodes viz. graphite $(C)$, copper-tungsten $(25-\mathrm{Cu} / 75-\mathrm{W})$ and tungsten $(\mathrm{W})$ were chosen for treating the DSS substrates in die-sinking EDM. Table 1 listed the specifications of all three electrodes. Initially, the emery paper (material: silicon carbide (SiC), grit-800) was employed for the surface finishing of the alloy plate. Further, the plate surface was cleaned with ethanol solution $\left(\mathrm{C}_{2} \mathrm{H}_{5} \mathrm{OH}\right)$ before ED machining.

Table 1. Properties of Graphite, Copper-Tungsten and Tungsten electrodes.

\begin{tabular}{cccc}
\hline Property & Graphite & Copper-Tungsten & Tungsten \\
\hline Diameter $(\mathrm{mm})$ & 10 & 10 & 10 \\
Density $\left(\mathrm{g} / \mathrm{cm}^{3}\right)$ & 2.26 & 14.5 & 18.8 \\
Melting point $\left({ }^{\circ} \mathrm{C}\right)$ & 3650 & 3410 & 3400 \\
Electrical resistivity $(\Omega \mathrm{cm})$ & $6.0 \times 10^{-3}$ & 4.5 & $5.6 \times 10^{-3}$ \\
Thermal conductivity $(\mathrm{W} / \mathrm{mK})$ & 24 & 189 & 163.3 \\
Thermal expansion coefficient $(\mu \mathrm{m} / \mathrm{mK})$ & 6 & 11.7 & 4.5 \\
Specific heat capacity $\left(\mathrm{J} / \mathrm{Kg}{ }^{\circ} \mathrm{C}\right)$ & 720 & 214 & 133 \\
Hardness $(\mathrm{HB})$ & 10 & 195 & 2570 \\
\hline
\end{tabular}

\subsection{Design of Experiment}

The Taguchi methodology was used to design the experimental array. In this investigation, an orthogonal array of L18 mixed-level design matrix was used to scrutinize the effects of five controllable parameters on two responses i.e., MRR, and SR. The chosen process parameters and their corresponding levels are tabulated in Table 2. The Minitab-17 statistical software was used to prepare the experimental design matrix. Further, analysis of variance (ANOVA) was utilized to analyze the dominance of process parameters on the MRR and SR.

Table 2. Parameters descriptions and values.

\begin{tabular}{ccccc}
\hline \multirow{2}{*}{ Parameter } & Units & \multicolumn{3}{c}{ Levels } \\
\cline { 3 - 5 } & & Level 1 & Level 2 & Level 3 \\
\hline Current (I) & ampere & 5 & 10 & 16 \\
Pulse-on-time (P-on) & $\mu$-seconds & 60 & 150 & 200 \\
Pulse-off-time (P-off) & $\mu$-seconds & 60 & 150 & 200 \\
Electrode & - & Gr & W & W-Cu \\
Dielectric medium & - & EDM oil & Deionized water & - \\
\hline
\end{tabular}

\subsection{Experimental Procedure}

All the experimental trials were performed on a die-sinker EDM (Electronica, India: Smart ZNC S50) with constant gap voltage $(140 \mathrm{~V})$ and machining depth $(0.5 \mathrm{~mm})$ for each run. Also, negative polarity (tool $(+)$ workpiece $(-))$ has opted throughout the experimentation. The material removal 
process during the EDM technique depends upon the generation of heat on the substrate due to the abundance of electric sparks between the electrode $[29,30]$. Both tool electrode as well as alloy substrate immersed in the dielectric fluid tank that provides proper stability during this thermo-electric process.

An in-house fabricated tank $\left(18^{\prime \prime} \times 18^{\prime \prime} \times 24^{\prime \prime}\right)$ was used of capacity 10 liters, containing a stirrer and circulation pump for appropriate flushing and avoiding debris within the working area. Figure 1 represented the schematic arrangement of EDM, experimental set up of machining and FE-SEM image of un-machined DSS-2205 substrate.

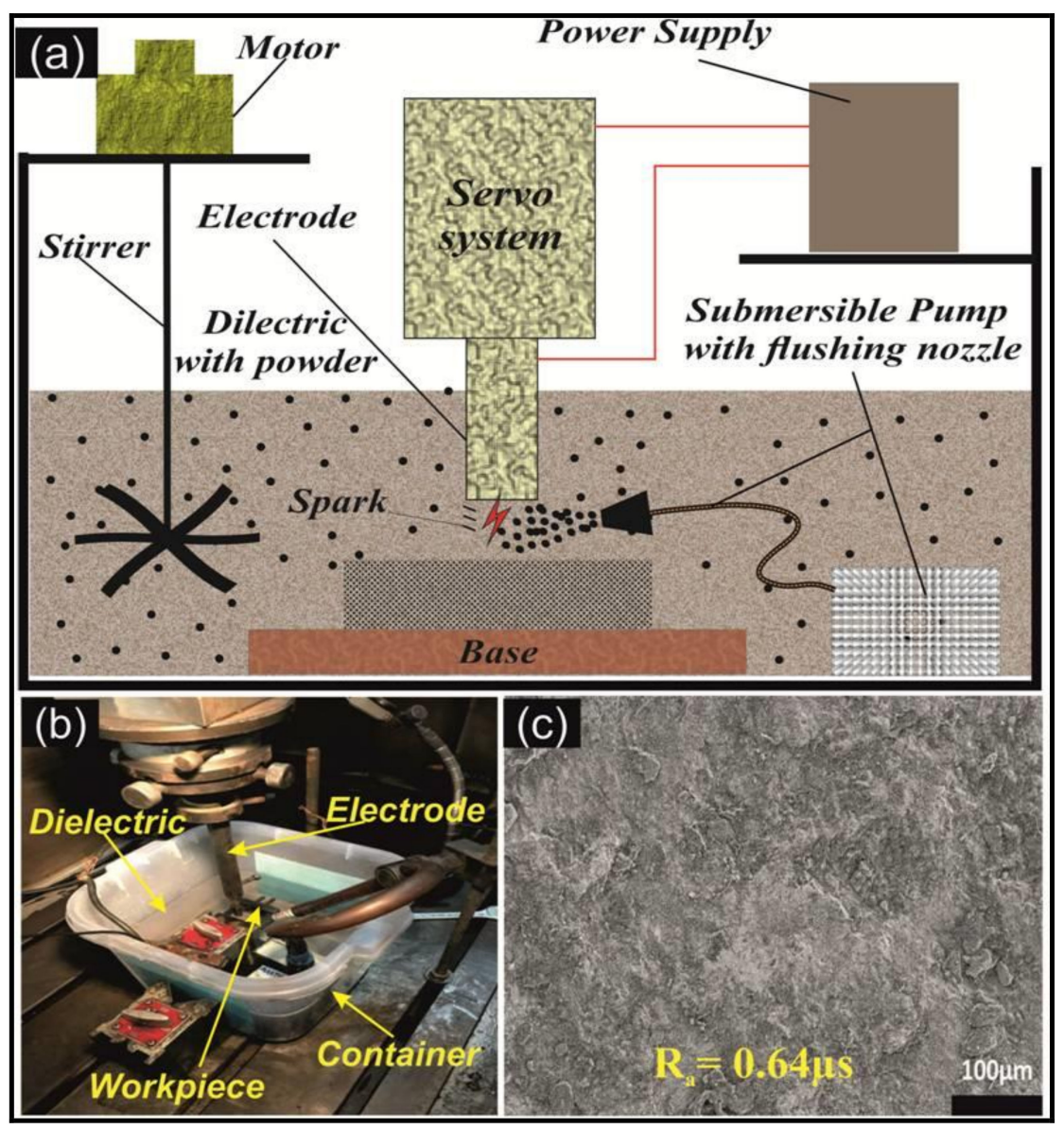

Figure 1. (a) Schematic arrangement of EDM; (b) Pictorial view of experimental set up of machining; (c) FE-SEM image of un-machined DSS-2205 substrate $(\mathrm{Ra}=0.64 \mu \mathrm{s})$.

\subsection{Calculations of Material Removal Rate (MRR) and Surface Roughness (SR)}

The weight of the workpiece was measured before and after each trial using a precise weighing balance (Citizen CY220) for calculating the MRR using Equation (1).

$$
\operatorname{MRR}\left(\mathrm{mm}^{3} / \mathrm{min} .\right)=\frac{\left(\mathrm{w}_{2}-\mathrm{w}_{1}\right) \times 1000}{\rho \times t}
$$

where;

" $\mathrm{w}_{2}$ and $\mathrm{w}_{1}$ " correspond to the workpiece weight $(\mathrm{g})$ before and after each trial,

" $\rho$ " is the density of workpiece, and

" $t$ " (minutes) is the machining time.

The other output response i.e., surface roughness of the machined DSS substrates were measured using the Mitutoyo SJ-201 surface profilometer. The roughness of each machined sample was 
measured diametrically at three different points, and an average value was considered (Ra) for further investigation.

\subsection{FE-SEM, EDX and XRD Analysis}

After machining, the morphology of the surface was examined using FE-SEM (Hitachi SU-8810, Japan) at $11.0 \mathrm{kV}$ of accelerating voltage. FE-SEM was also utilized to examine the surface after the wear test and also for the recast layer thickness. The phase transformation analysis (XRD; PANalytical $X^{\prime}$ Pert Pro MPD, The Netherlands) was performed using $\mathrm{Cu}-\mathrm{K} \alpha \mathrm{X}$-ray radiation, and with generator settings of $40 \mathrm{~mA}$ and $45 \mathrm{kV}$. The elemental composition of the machined DSS-2205 specimen was analyzed via energy-dispersive X-ray spectroscopy (EDX; incorporated with FE-SEM) to observe the EDMed samples.

\subsection{Investigation of Tribological Characteristics}

Additionally, the sample exhibiting superior output responses i.e., high material removal and roughness were investigated for their tribological performance using a pin-on-disc type tribometer (DUCOM Instrument, Bangalore, India). ASTM G99-17, a standard for pin-on-disc wear analysis was followed and the EN31 steel disc of diameter $120 \mathrm{~mm}$ and thickness $20 \mathrm{~mm}$ was used to test the wear of the specimens at $100 \mathrm{rpm}$ rotation speed. Test lubricant (ringer solution), track diameter (80 mm), steady load (70 N) and running time (3600 s) remains constant for each experimental run. The working operation of the tribometer, and calculations of wear, friction values obtained via associated software (TR-20LE) built-in with the attached computer system.

\subsection{Microhardness and Recast Layer Thickness Measurement}

German made; Mitutoyo microhardness tester was used under low-force hardness scale (HV 0.2) with a test force-load of $1.96 \mathrm{~N}$ for a dwell time of $10 \mathrm{~s}$. The microhardness was figured thrice at distinct points, and an average value was noted for the calculation. The EDMed sample with superior output responses and correlated to tribological performance was cut cross-sectionally for measuring the recast layer thickness. The diamond paste was utilized for the mirror-polished of the substrate. The surface morphological investigation of a cross-section of the EDMed substrate depicted the recast layer thickness that was measured at five different positions at the transverse section and its average value was recorded.

\subsection{Surface Wettability (Contact Angle Measurement)}

The surface wettability of the alloy is the crucial property that impacts the other significant characteristics and also influences the enduring usage of the alloy substrate [31]. The hydrophobic or hydrophilic nature of the surface represented the wettability which was measured by the water contact angle (WCA). If WCA is greater than $90^{\circ}$, the surface is represented as hydrophobic, whereas, the angle lesser than $90^{\circ}$ with the surface is considered as hydrophilic [32]. The wettability investigation was executed by utilizing a contact angle goniometer (Model 790; make: Rame-Hart instrument, USA) where the contact angle was computed in an environmental chamber through the sessile drop technique at $28{ }^{\circ} \mathrm{C}$. The surface was cleaned with acetone solution before the experimentation. The contact angle of the substrate was measured at five different positions and an average value considered and reported as WCA. The digital camera captured a $20 \mu \mathrm{L}$ distilled water profile of the droplet set on top of the substrate surface by a Gilmont microsyringe.

\section{Results and Discussion}

The present study predicts and optimizes the ED machining performance parameters for duplex stainless steel (DSS-2205). All the experimental trials were carried out thrice (i.e., $18 \times 3=54$ runs) to minimize the error and for precise outcomes. The respective results in Table 3 signified the average 
material removal rate and surface roughness values attained from each experimental run, followed by the standard deviation (i.e., Avg. \pm S.D). Further, these results were investigated statistically via ANOVA and the most significant parameters that influence these outcomes were investigated.

Table 3. Experimental L18 array design matrix and output response observations.

\begin{tabular}{|c|c|c|c|c|c|c|c|c|c|}
\hline \multirow[b]{2}{*}{$\begin{array}{l}\text { Exp. } \\
\text { Trial }\end{array}$} & \multicolumn{5}{|c|}{ Levels of Controllable Parameters } & \multicolumn{4}{|c|}{ Output Responses } \\
\hline & $\begin{array}{c}\text { I } \\
\text { (A) }\end{array}$ & $\begin{array}{l}\text { P-on } \\
(\mu s)\end{array}$ & $\begin{array}{c}\text { P-off } \\
(\mu s)\end{array}$ & Electrode & $\begin{array}{l}\text { Dielectric } \\
\text { Medium }\end{array}$ & $\begin{array}{c}\text { MRR } \\
\left(\mathrm{mm}^{3} / \mathrm{min}\right) \\
\text { Avg. } \pm \mathrm{SD}\end{array}$ & $\begin{array}{l}\text { S/N Ratio } \\
\text { (MRR) }\end{array}$ & $\begin{array}{c}\text { SR } \\
(\mu \mathrm{m}) \\
\text { Avg. } \pm S D\end{array}$ & $\begin{array}{c}\text { S/N } \\
\text { Ratio } \\
(\mathrm{SR})\end{array}$ \\
\hline 1. & 1 & 1 & 1 & 1 & 1 & $4.06 \pm 0.23$ & 12.1585 & $0.14 \pm 0.05$ & -17.68 \\
\hline 2. & 1 & 2 & 2 & 2 & 1 & $3.85 \pm 0.29$ & 11.6704 & $0.56 \pm 0.07$ & -5.17 \\
\hline 3. & 1 & 3 & 3 & 3 & 1 & $3.98 \pm 0.14$ & 11.9995 & $0.71 \pm 0.07$ & -3.00 \\
\hline 4. & 2 & 1 & 1 & 2 & 1 & $13.41 \pm 0.96$ & 22.5151 & $0.26 \pm 0.02$ & -11.75 \\
\hline 5. & 2 & 2 & 2 & 3 & 1 & $18.38 \pm 0.49$ & 25.2822 & $1.0 \pm 0.09$ & -0.36 \\
\hline 6. & 2 & 3 & 3 & 1 & 1 & $10.31 \pm 0.13$ & 20.2695 & $0.2 \pm 0.04$ & -17.25 \\
\hline 7. & 3 & 1 & 2 & 1 & 1 & $14.49 \pm 0.21$ & 23.2229 & $0.13 \pm 0.04$ & -19.02 \\
\hline 8. & 3 & 2 & 3 & 2 & 1 & $27.82 \pm 0.04$ & 28.8871 & $1.4 \pm 0.08$ & 2.79 \\
\hline 9. & 3 & 3 & 1 & 3 & 1 & $39.4 \pm 0.98$ & 31.9058 & $1.21 \pm 0.06$ & 1.65 \\
\hline 10. & 1 & 1 & 3 & 3 & 2 & $3.1 \pm 0.05$ & 9.8251 & $0.23 \pm 0.04$ & -13.14 \\
\hline 11. & 1 & 2 & 1 & 1 & 2 & $4.36 \pm 0.67$ & 12.6451 & $0.40 \pm 0.01$ & -7.82 \\
\hline 12. & 1 & 3 & 2 & 2 & 2 & $0.14 \pm 0.04$ & -17.2078 & $0.30 \pm 0.06$ & -11.44 \\
\hline 13. & 2 & 1 & 2 & 3 & 2 & $4.29 \pm 0.6$ & 12.5315 & $0.19 \pm 0.05$ & -14.93 \\
\hline 14. & 2 & 2 & 3 & 1 & 2 & $5.38 \pm 0.37$ & 14.5921 & $0.08 \pm 0.02$ & -22.50 \\
\hline 15. & 2 & 3 & 1 & 2 & 2 & $1.01 \pm 0.04$ & 0.1421 & $0.18 \pm 0.03$ & -15.14 \\
\hline 16. & 3 & 1 & 3 & 2 & 2 & $7.45 \pm 0.45$ & 17.4242 & $0.28 \pm 0.05$ & -11.27 \\
\hline 17. & 3 & 2 & 1 & 3 & 2 & $28.18 \pm 0.66$ & 28.9952 & $1.3 \pm 0.08$ & 2.24 \\
\hline 18. & 3 & 3 & 2 & 1 & 2 & $12.84 \pm 0.30$ & 22.1710 & $0.26 \pm 0.02$ & -11.78 \\
\hline
\end{tabular}

\subsection{MRR Results Investigation by ANOVA}

Table 4 detailed the ANOVA results for the material removal rate of DSS-2205 alloy. The F-values, with a confidence level of $95 \%$, acquainted the influential factors that extremely affect the substrate surface responses after machining. The parameters with higher F-value reveal its superior impact on the output machining responses. Likewise, the $p$-value indicated the significance level of the input controllable factor. The signal-to-noise ratios ( $\mathrm{S} / \mathrm{N}$ ratios) results of MRR represented current as of the most significant factor that majorly contributes in removing the material from DSS-2205 alloy, followed by the dielectric medium and electrode material.

Table 4. ANOVA for Material Removal Rate.

\begin{tabular}{ccccccc}
\hline Source & DF & $\begin{array}{c}\text { Sum of } \\
\text { Squares }\end{array}$ & $\begin{array}{c}\text { Mean } \\
\text { Squares }\end{array}$ & F-Value & $p$-Value & $\begin{array}{c}\text { \% } \\
\text { Contribution }\end{array}$ \\
\hline Current & 2 & 1036.56 & 518.28 & 18.34 & $0.001^{*}$ & 45.18 \\
Pulse-on-time & 2 & 232.70 & 116.35 & 4.12 & 0.059 & 10.14 \\
Pulse-off-time & 2 & 89.57 & 44.78 & 1.58 & 0.263 & 3.90 \\
Electrode & 2 & 290.77 & 145.39 & 5.15 & $0.037^{*}$ & 12.67 \\
Dielectric medium & 1 & 418.50 & 418.50 & 14.81 & $0.005^{*}$ & 18.24 \\
Error & 8 & 226.05 & 28.26 & & & \\
Total & 17 & 2294.14 & &
\end{tabular}

However, the $p$-values ( $>0.05$ ) for pulse-on-time and pulse-off-time are not considerable; consequently, both are in-significant factors for machining of DSS-2205 under the selected range of parametric settings. The machined alloy sample as per the parametric settings of trial 9, demonstrates the highest material removal rate $\left(39.4 \pm 0.98 \mathrm{~mm}^{3} / \mathrm{min}\right)$. These results are in accordance with previously reported studies, where researchers reported discharge current, pulse-on duration, dielectric type and electrode material as the most significant factors for the EDM performance affecting the output responses [33-35]. The optimum parameters for maximum material removal rate of DSS substrates 
were examined from the $\mathrm{S} / \mathrm{N}$ ratios plot (Figure 2) as $16 \mathrm{~A}$ of current, P-on $=150 \mu \mathrm{s}, \mathrm{P}$-off $=60 \mu \mathrm{s}$, and use of W-Cu electrode in EDM oil.

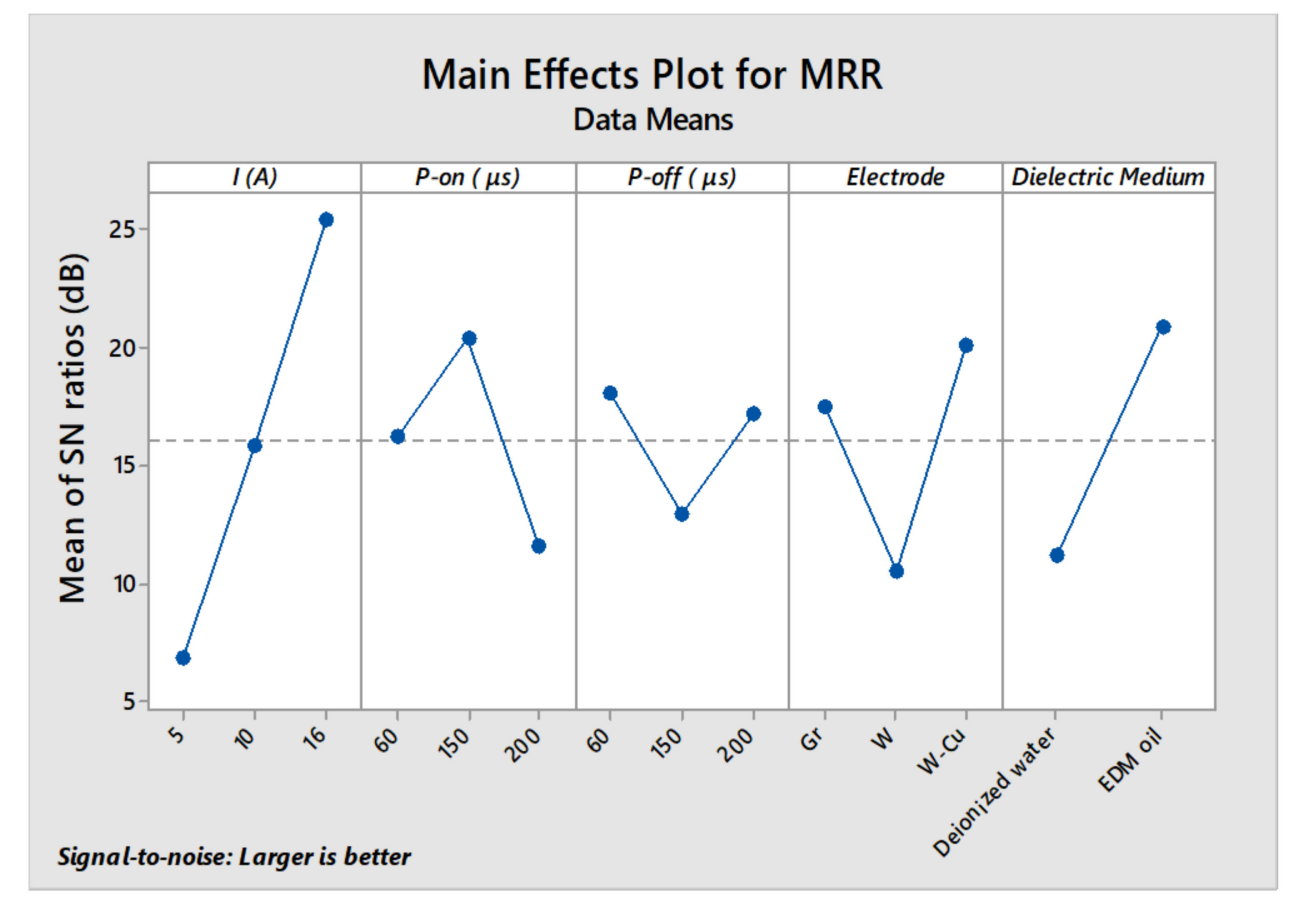

Figure 2. Main effect plot for $\mathrm{S} / \mathrm{N}$ ratios of Material Removal Rate.

\subsection{SR Results Investigation by ANOVA}

Table 5 depicts the analysis of variance results for the input factors in order to observe their dominance affecting the $\mathrm{S} / \mathrm{N}$ ratios outcome of the surface roughness. From ANOVA results, electrode material ( $p$-value: 0.001$)$ was the most significant factor with a confidence level of $95 \%$ that influences the surface roughness of the machined substrates. The other factors such as, pulse-on-time ( $p$-value: $0.003)$, current ( $p$-value: 0.011$)$ and dielectric medium ( $p$-value: 0.033 ) also play a momentous role in producing the rough surfaces. The $\mathrm{S} / \mathrm{N}$ ratios plot (Figure 3 ) disclosed that the DSS alloy samples machined in EDM oil with copper- tungsten $(\mathrm{Cu} / \mathrm{W})$ electrode at $16 \mathrm{~A}$ current, $150 \mu$ s pulse-on-time with a $60 \mu$ s pulse-off-time provided the more substantial surface roughness responses.

Table 5. ANOVA for Surface Roughness.

\begin{tabular}{ccccccc}
\hline Source & DF & $\begin{array}{c}\text { Sum of } \\
\text { Squares }\end{array}$ & $\begin{array}{c}\text { Mean } \\
\text { Squares }\end{array}$ & F-Value & $p$-Value & $\begin{array}{c}\text { \% } \\
\text { Contribution }\end{array}$ \\
\hline Current & 2 & 180.62 & 90.31 & 8.31 & $0.011^{*}$ & 17.39 \\
Pulse-on-time & 2 & 271.23 & 135.62 & 12.48 & $0.003^{*}$ & 26.11 \\
Pulse-off-time & 2 & 25.38 & 12.69 & 1.17 & 0.359 & 2.50 \\
Electrode & 2 & 402.08 & 201.04 & 18.50 & $0.001^{*}$ & 38.73 \\
Dielectric medium & 1 & 72.03 & 72.03 & 6.63 & $0.033^{*}$ & 6.94 \\
Error & 8 & 86.94 & 10.87 & & & \\
Total & 17 & 1038.28 & & & & \\
\hline
\end{tabular}

${ }^{*}$ Significant at $95 \%$ confidence level 


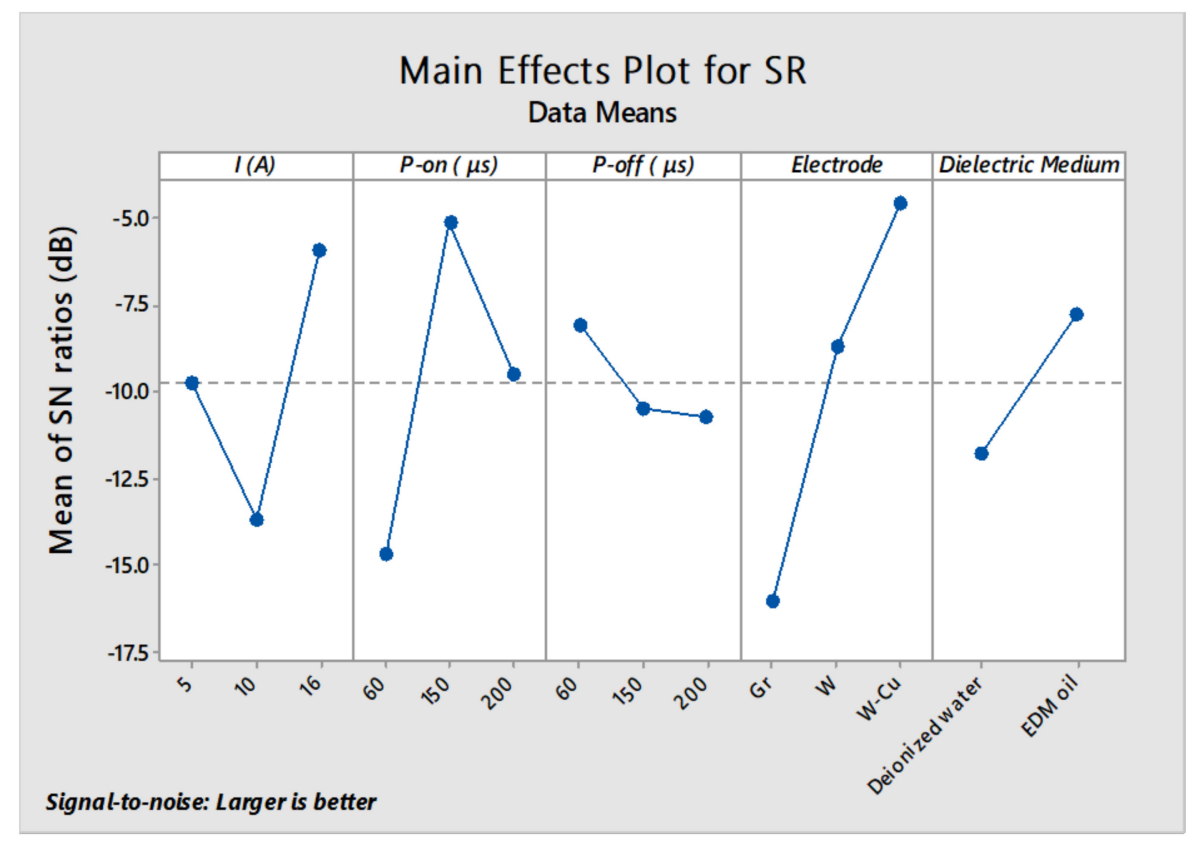

Figure 3. Main effect plot for $\mathrm{S} / \mathrm{N}$ ratios of Surface Roughness.

Among all the trials, specimen machined according to the parameter set of trial 8 exhibits a highly rough surface $(\mathrm{Ra}=1.4 \pm 0.08 \mu \mathrm{m})$. The results showed that some other machined substrates also have improved surface roughness as compared to the un-machined surface $(\mathrm{Ra}=0.64 \mu \mathrm{s})$. These outcomes also endorsed the prominence of EDM in the biomedical field, where surface roughness plays a crucial role in the adequate engagement of human tissues and bones with implant surface [36-38].

\subsection{Surface Morphology and Compositional Analysis of Machined Surface}

Figure 4 illustrates the surface morphology of the EDMed substrates (trial 8 and trial 9) exhibiting excellent results of material removal rate and surface roughness. Both the machined substrates showed micro and macropores and re-solidified metallic droplets on the surface. It is observable from the images (Figure $4 \mathrm{a}, \mathrm{b}$ ) that higher spark energy (Spark Energy $=$ Current $\times \mathrm{P}$-on $\times$ Voltage) generate pores along with small peaks and valleys on the EDT surface $[39,40]$. The presence of the pores and molten metal droplets on the surface promotes the biological performance of the substrates [41].
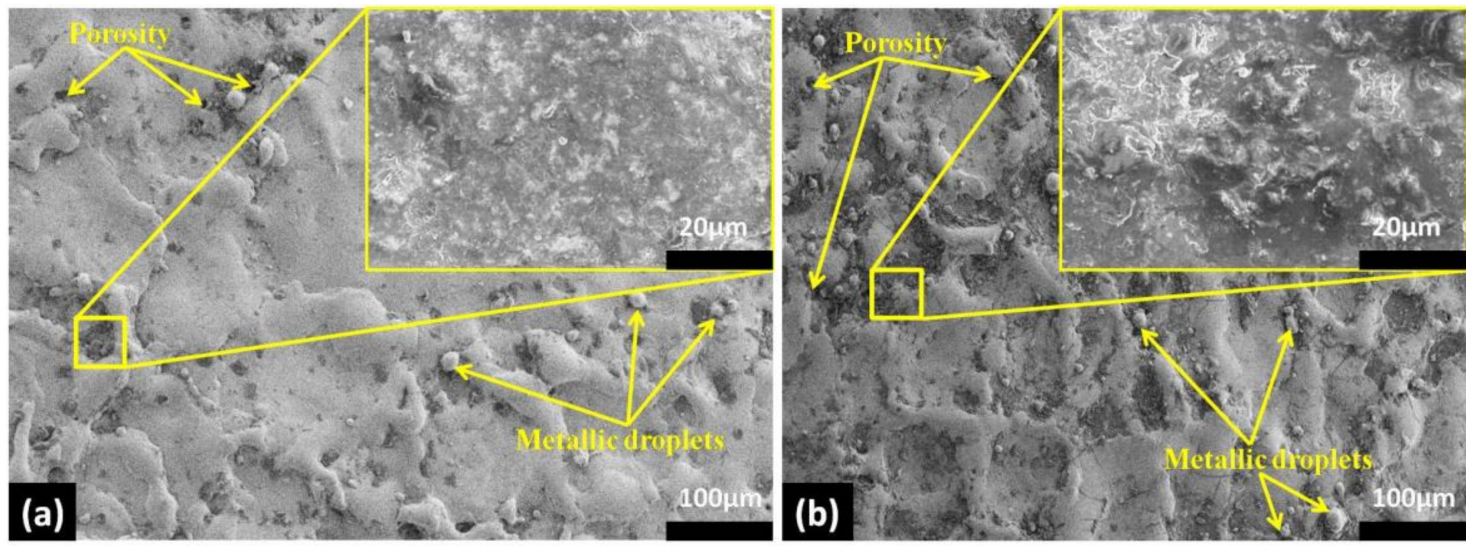

Figure 4. FE-SEM images illustrate surface roughness (a) Sample $8(\mathrm{Ra}=1.4 \mu \mathrm{s})$, and (b) Sample 9 $(\mathrm{Ra}=1.21 \mu \mathrm{s})$.

The EDX spectrum of the EDMed sample (trial 9) exhibiting higher material removal and surface roughness represented in Figure 5a. The presence of basic elements of DSS alloys viz. Fe, Ni, Cr, 
Mo, Mn and C was observed on the surface. Moreover, apart from base elements of alloy, the high percentage of oxygen element was also observed on the machined substrate. The EDX outcome of phase transformation of the machined substrate is also affirmed by the $\mathrm{XRD}$ pattern (Figure $5 b$ ). The formation of compounds viz. rhombohedral structured iron oxide $\left(\mathrm{Fe}_{2} \mathrm{O}_{3}\right)$, major phase of $\mathrm{CrMn}_{1.5} \mathrm{O}_{4}$, tetragonal structured iron-chromium ( $\mathrm{Fe}-\mathrm{Cr})$, hexagonal structured chromium oxide $\left(\mathrm{Cr}_{2} \mathrm{O}_{3}\right)$ and tungsten carbide (WC) on the machined surface improves the wear resistance of the alloy. The presence of these oxides and carbides on the surface also improves the biocompatibility of alloy substrate due to which DSS alloy can also utilize in the biomedical domain.

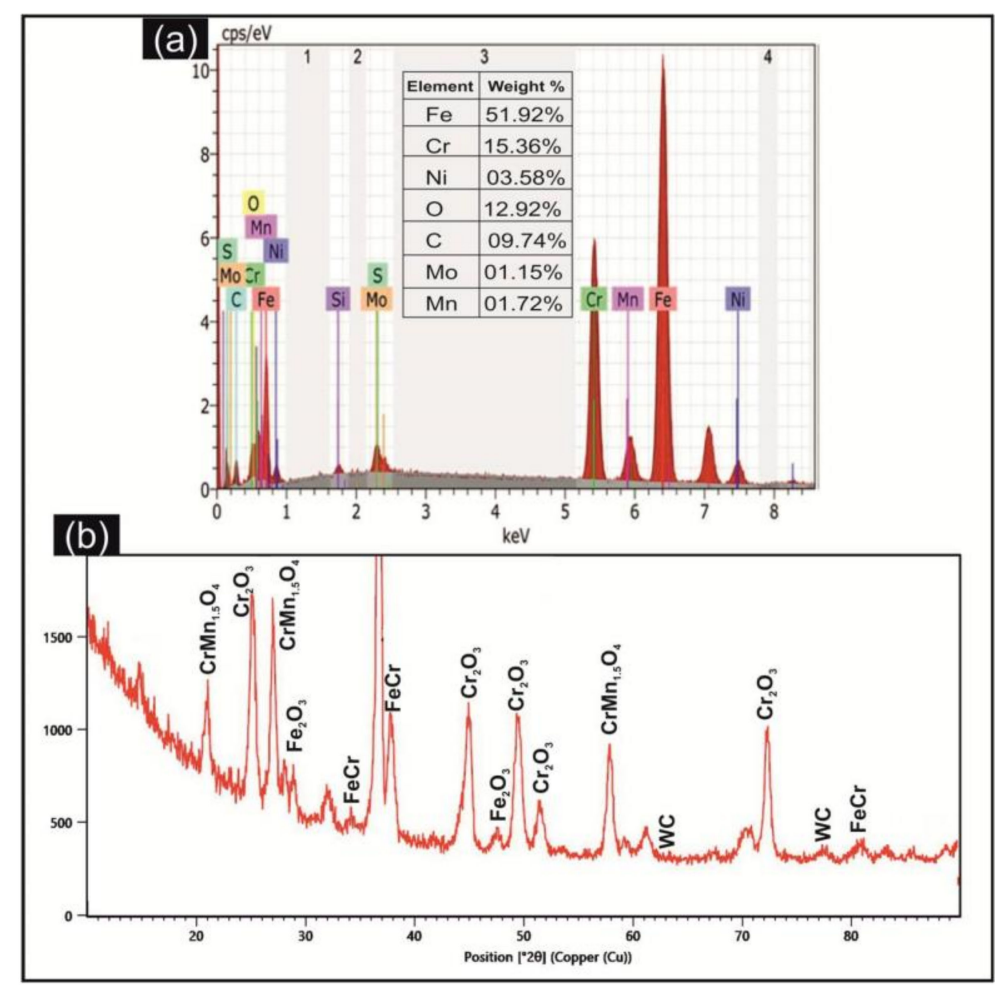

Figure 5. (a) EDS elemental spectrum and (b) XRD pattern of EDMed substrate.

\subsection{Tribological Performance Analysis of Machined Surface}

The machined sample with superior outcomes i.e., trial 9 was further assessed for their tribological performance. Moreover, the wear rate and coefficient of friction of the EDMed substrates were compared with the untreated substrate of DSS alloy. Table 6 demonstrates the wear characteristics of both treated and untreated substrates. It has been noticed that the wear rate of an untreated substrate $\left(3.52 \pm 0.15 \times 10^{-5} \mathrm{~mm}^{3} / \mathrm{Nm}\right)$ was higher than the EDMed substrate $\left(1.23 \pm 0.11 \times 10^{-5} \mathrm{~mm}^{3} / \mathrm{Nm}\right)$. Figure 6a represented the wear rate comparison of both specimens, whereas, the coefficient of friction with time for both pin substrates is showed in Figure $6 \mathrm{~b}$. It has been portrayed that the co-efficient of friction $(\mu)$ value of the un-machined specimen $\left(\mu_{\text {average }}=0.32\right)$ is greater than the EDMed substrate $\left(\mu_{\text {average }}=0.23\right)$.

Table 6. Wear rate and co-efficient of friction (COF) of samples.

\begin{tabular}{|c|c|c|c|c|c|c|c|c|c|}
\hline \multirow[b]{2}{*}{ Sr. No. } & \multirow[b]{2}{*}{ Sample } & \multicolumn{2}{|c|}{$\mathrm{N}=1$} & \multicolumn{2}{|c|}{$\mathrm{N}=2$} & \multicolumn{2}{|c|}{$N=3$} & \multicolumn{2}{|c|}{ Avg. \pm SD } \\
\hline & & $\mathrm{COF}$ & $\begin{array}{l}\text { Wear Rate } \\
\left(\mathrm{mm}^{3} / \mathrm{Nm}\right)\end{array}$ & $\mathrm{COF}$ & $\begin{array}{l}\text { Wear Rate } \\
\left(\mathrm{mm}^{3} / \mathrm{Nm}\right)\end{array}$ & $\mathrm{COF}$ & $\begin{array}{l}\text { Wear Rate } \\
\left(\mathrm{mm}^{3} / \mathrm{Nm}\right)\end{array}$ & $\mathrm{COF}$ & $\begin{array}{l}\text { Wear Rate } \\
\left(\mathrm{mm}^{3} / \mathrm{Nm}\right)\end{array}$ \\
\hline 1. & Untreated & 0.317 & $3.52 \times 10^{-5}$ & 0.322 & $3.68 \times 10^{-5}$ & 0.312 & $3.37 \times 10^{-5}$ & $0.317 \pm 0.005$ & $3.52 \times 10^{-5} \pm 0.15$ \\
\hline 2. & Treated & 0.237 & $1.05 \times 10^{-5}$ & 0.246 & $1.13 \times 10^{-5}$ & 0.231 & $0.97 \times 10^{-5}$ & $0.238 \pm 0.007$ & $1.05 \times 10^{-5} \pm 0.08$ \\
\hline
\end{tabular}




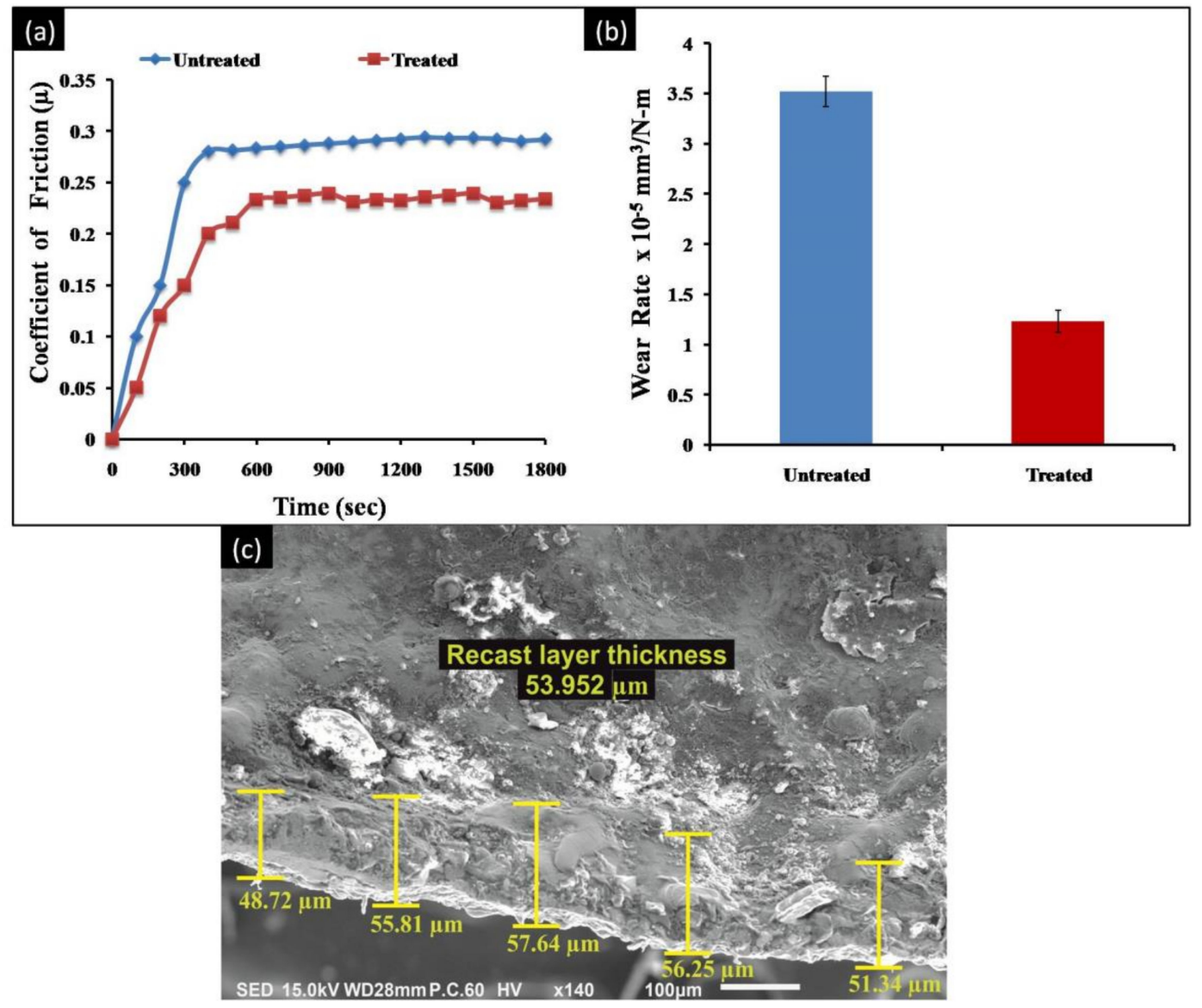

Figure 6. (a) Wear rate comparison of untreated and treated samples; (b) Variation of the co-efficient of friction of samples; (c) Cross-section of the EDMed substrate.

Wear appearances for the EDMed and un-machined specimens were depicted by FE-SEM images. The un-machined surface was witnessed with flakes, pits and deep grooves (Figure 7a). However, the machined specimen was found with black patches that symbolized the tribochemical reaction (specimen surface wear in the high oxide atmosphere) (Figure $7 \mathrm{~b}$ ). Moreover, the machined surface was noticed with light scratches and no delamination that reveal the high wear resistance of the substrate [42-44]. Evidently, electric discharge machining at elevated temperature results in the chemical reaction between the dielectric fluid and the workpiece material elements. It results in the formation of carbide and oxide layers on the substrate that improves the wear resistance of the surface.
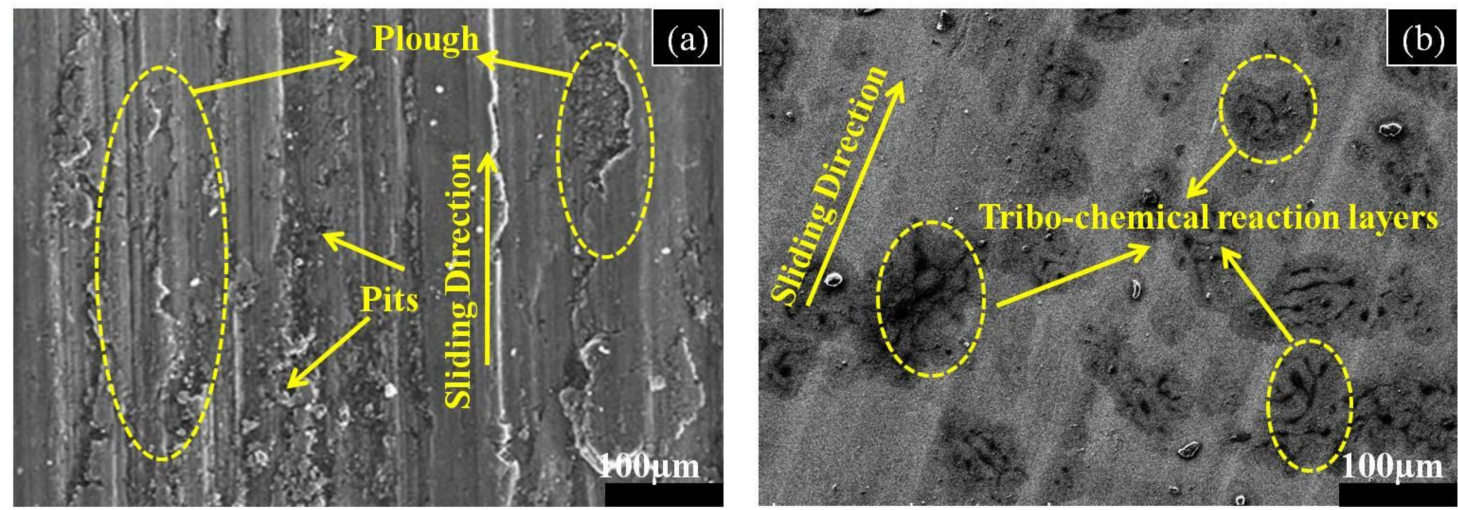

Figure 7. FE-SEM images represent the wear appearances of (a) Untreated substrate; (b) EDMed substrate. 


\subsection{Analysis of Microhardness and Recast Layer Thickness}

Micro-hardness results are also in-line with wear resistance outcomes. EDMed DSS substrate (trial 9) showed $487 \mathrm{HV}_{0.2}$ micro-hardness, which was 1.46 (approx.) times better than the un-machined surface $\left(334 \mathrm{HV}_{0.2}\right.$ ) of DSS alloy. These results were further affirmed by the investigation of the recast layer thickness of the machined surface. The cross-section image of the treated substrate was witnessed with the thick recast layer $(53.952 \mu \mathrm{m})$ on the surface (Figure $6 \mathrm{c}$ ). The re-deposition of melting material droplets from a working specimen as well as a tool electrode could be the possible reason for the recast layer on the machined substrate $[45,46]$. The outcomes portrayed improved resistance towards wear and micro-hardness of the machined substrate in comparison with an untreated substrate that admires the EDMed substrate in various industrial applications.

\subsection{Surface Wettability Analysis}

The WCA scrutinization demonstrated the hydrophobic or hydrophilic nature of tested substrates. The contact angles procured on untreated and treated substrates after 10s are represented in Figure 8. The results clearly showed that the EDM considerably improved the wettability of the surface. The WCA of the machined surface was $78.27 \pm 0.41^{\circ}$ respectively signifying the hydrophilic surface. The un-machined surface was hydrophobic with WCA of $105.96 \pm 0.52^{\circ}$ (above $90^{\circ}$ ). These results were in accordance with surface roughness outcomes. However, the surface roughness of the substrate has a huge impact on the wettability of the surface. Some researchers reported the direct relation between surface roughness and wettability [47]. The increased surface roughness leads to enhance the surface free energy by offering the expanded surface area to water droplet [48,49]. Therefore, surface alteration enhances the wetting responses of surface that endorse the machined substrate applications in the biomedical domain, lubrication and for different coatings [50,51].

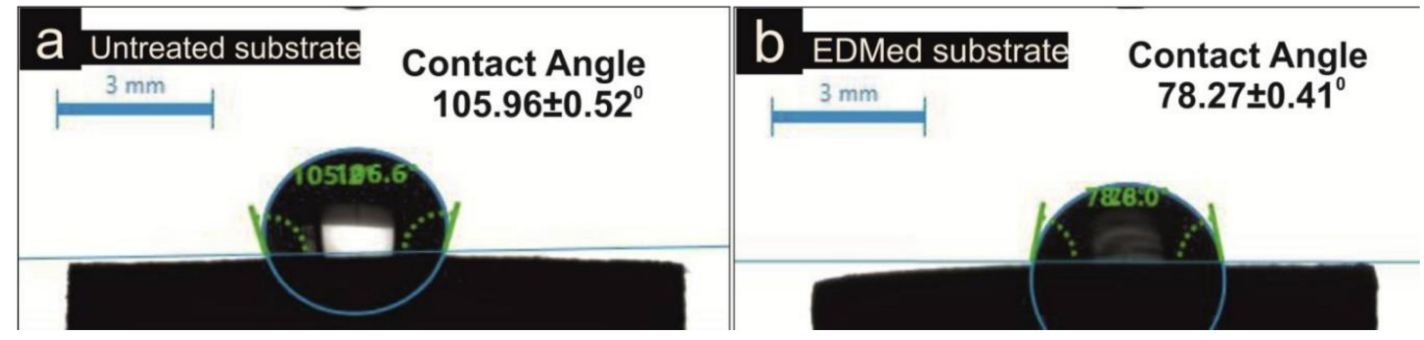

Figure 8. Contact angle illustration of (a) Untreated surface; (b) EDMed surface.

\section{Conclusions}

The present study described the processing of duplex stainless steel (DSS-2205) alloy by EDM using graphite, copper-tungsten and tungsten as electrodes in two different dielectric mediums, namely EDM oil and deionized water. Based on the result, following conclusions have been drawn.

The dominating factors depicting maximum material removal rate $\left(39.4 \pm 0.98 \mathrm{~mm}^{3} / \mathrm{min}\right)$ were current (contribution: 45.10\%), dielectric medium (contribution: 18.24\%), and electrode (contribution: $12.67 \%$ ).

The higher surface roughness accelerates the osseointegration process of bioimplant. The most significant parameters for higher surface roughness $(\mathrm{Ra}=1.4 \pm 0.08 \mu \mathrm{m})$ were electrode (contribution: $38.72 \%$ ), pulse-on-time (contribution: $26.11 \%$ ), and current (contribution: $17.39 \%$ ).

From the S/N ratios plot, the optimum parametric combinations for favorable MRR and SR values by ED machining of DSS substrate are, EDM oil as dielectric medium, W/Cu electrode and current at $16 \mathrm{~A}$, pulse-on-time at $150 \mu$ s coupled with the lowest pulse-off-time (i.e., $60 \mu \mathrm{s}$ ).

The FE-SEM and XRD examination confirmed the evenly distributed porous surface, and formation of oxides and other intermetallic compounds on the DSS-2205 surface machined at higher spark energy in the presence of EDM oil as a dielectric medium. 
Moreover, EDMed substrate with higher MRR and surface roughness also exhibited enhanced wear resistance and surface wettability responses as compared to untreated DSS alloy substrate. The results also illustrated that EDMed DSS-2205 could be employed in the biomedical field.

Author Contributions: Conceptualization, T.R.A., S.S.S. and A.M.; methodology, S.S.S. and T.R.A.; software, G.S. and S.D.; validation, A.M., G.S., K.R.M. and E.S.S.; formal analysis, T.R.A., E.S.S. and S.S.S.; investigation, A.M., G.S., S.D.; resources, S.S.S.; data curation, T.R.A., E.S.S. and S.S.S.; writing-original draft preparation, A.M. and G.S.; writing-review and editing, A.M., G.S., S.S.S. and T.R.A.; visualization, K.R.M., E.S.S., G.S., and A.M.; supervision, S.S.S. and T.R.A.; project administration, T.R.A., A.M. and S.S.S.; funding acquisition, T.R.A., E.S.S. and K.R.M. All authors have read and agreed to the published version of the manuscript.

Funding: This work was supported by Russian Science Foundation, grant number 20-79-00048.

Conflicts of Interest: The authors declare no conflict of interest. The funders had no role in the design of the study; in the collection, analyses, or interpretation of data; in the writing of the manuscript, or in the decision to publish the results.

\section{References}

1. Talla, G.; Gangopadhyay, S.; Biswas, C.K. Influence of graphite powder mixed EDM on the surface integrity characteristics of Inconel 625. Part. Sci. Technol. 2017, 35, 219-226. [CrossRef]

2. Singh, G.; Ablyaz, T.R.; Shlykov, E.S.; Muratov, K.R.; Bhui, A.S.; Sidhu, S.S. Enhancing corrosion and wear resistance of Ti6Al4V alloy using CNTs mixed electro-discharge process. Micromachines 2020, 11, 850. [CrossRef] [PubMed]

3. Rajeswari, R.; Shunmugam, M.S. Finishing performance of die-sinking EDM with ultrasonic vibration and powder addition through pulse train studies. Mach. Sci. Technol. 2019, 24, 245-273. [CrossRef]

4. Kumar, V.; Diyaley, S.; Chakraborty, S. Teaching-learning-based parametric optimization of an electrical discharge machining process. FU Ser. Mech. Eng. 2020, 18, 281-300. [CrossRef]

5. Mahajan, A.; Sidhu, S.S. Enhancing biocompatibility of $\mathrm{Co}-\mathrm{Cr}$ alloy implants via electrical discharge process. Mater. Technol. 2018, 33, 524-531. [CrossRef]

6. Singh, G.; Lamichhane, Y.; Bhui, A.S.; Sidhu, S.S.; Bains, P.S.; Mukhiya, P. Surface morphology and microhardness behavior of 316L in HAp-PMEDM. FU Ser. Mech. Eng. 2019, 17, 445-454. [CrossRef]

7. Umar-Farooq, M.; Pervez-Mughal, M.; Ahmed, N.; Ahmad-Mufti, N.; Al-Ahmari, A.M.; He, Y. On the investigation of surface integrity of Ti6Al4V ELI using Si-mixed electric discharge machining. Materials 2020, 13, 1549. [CrossRef]

8. Al-Amin, M.; Abdul-Rani, A.M.; Abdu-Aliyu, A.A.; Abdul-Razak, M.A.; Hastuty, S.; Bryant, M.G. Powder mixed-EDM for potential biomedical applications: A critical review. Mater. Manuf. Process. 2020, 1-23. [CrossRef]

9. Al-Amin, M.; Abdul-Rani, A.M.; Abdu-Aliyu, A.A.; Bryant, M.G.; Danish, M.; Ahmad, A. Bio-ceramic coatings adhesion and roughness of biomaterials through PM-EDM: A comprehensive review. Mater. Manuf. Process. 2020, 35, 1157-1180. [CrossRef]

10. Devgan, S.; Sidhu, S.S. Surface modification of $\beta$-type titanium with multi-walled CNTs $/ \mu$-HAp powder mixed Electro Discharge Treatment process. Mater. Chem. Phys. 2020, 239, 122005. [CrossRef]

11. D’Urso, G.; Giardini, C.; Maccarini, G.; Quarto, M.; Ravasio, C. Analysis of the surface quality of steel and ceramic materials machined by micro-EDM. In Proceedings of the 18th International Conference of the European Society for Precision Engineering and Nanotechnology, EUSPEN, Venice, Italy, 4-8 June 2018; pp. 431-432.

12. Razavykia, A.; Yavari, M.R.; Iranmanesh, S.; Esmaeilzadeh, A. Effect of electrode material and electrical discharge machining parameters on machining of Co-Cr-Mo. Int. J. Mech. Mechatron. Eng. 2016, 16, 53-61.

13. Mahajan, A.; Sidhu, S.S. Potential of electrical discharge treatment to enhance the in vitro cytocompatibility and tribological performance of Co-Cr implant. J. Mater. Res. 2019, 34, 2837-2847. [CrossRef]

14. Philip, J.T.; Kumar, D.; Mathew, J.; Kuriachen, B. Experimental investigations on the tribological performance of electric discharge alloyed Ti-6Al-4V at 200-600 ${ }^{\circ} \mathrm{C}$. J. Tribol. 2020, 142, 061702. [CrossRef]

15. Devgan, S.; Sidhu, S.S. Potential of electrical discharge treatment incorporating MWCNTs to enhance the corrosion performance of the $\beta$-titanium alloy. Appl. Phys. A 2020, 126, 211. [CrossRef] 
16. Simao, J.; Lee, H.G.; Aspinwall, D.K.; Dewes, R.C.; Aspinwall, E.M. Workpiece surface modification using electrical discharge machining. Int. J. Mach. Tools Manuf. 2003, 43, 121-128. [CrossRef]

17. Singh, G.; Sidhu, S.S.; Bains, P.S.; Bhui, A.S. Improving microhardness and wear resistance of $316 \mathrm{~L}^{\text {by }} \mathrm{TiO}_{2}$ powder mixed electro-discharge treatment. Mater. Res. Express. 2019, 6, 086501. [CrossRef]

18. Pramanik, A.; Basak, A.K.; Dixit, A.R.; Chattopadhyaya, S. Processing of duplex stainless steel by WEDM. Mater. Manuf. Process. 2018, 33, 1559-1567. [CrossRef]

19. Alshemary, A.; Pramanik, A.; Basak, A.K.; Littlefair, G. Accuracy of duplex stainless steel feature generated by electrical discharge machining (EDM). Measurement 2018, 130, 137-144. [CrossRef]

20. Rajmohan, K.; Kumar, A.S. Experimental investigation and prediction of optimum process parameters of micro-wire-cut EDM of 2205 DSS. Int. J. Adv. Manuf. Technol. 2017, 93, 187-201. [CrossRef]

21. Rajaram, S.; Rajkumar, G.; Balasundaram, R.; Srinivasan, D. Experimental investigation of drilling small hole on duplex stainless steel (SS 2205) using EDM. Mech. Mech. Eng. 2019, 23, 98-102. [CrossRef]

22. Mahajan, A.; Sidhu, S.S.; Devgan, S. Examination of hemocompatibility and corrosion resistance of electrical discharge-treated duplex stainless steel (DSS-2205) for biomedical applications. Appl. Phys. A 2020, 126, 737. [CrossRef]

23. Khanra, A.K.; Sarkar, B.R.; Bhattacharya, B.; Pathak, L.C.; Godkhindi, M.M. Performance of $\mathrm{ZrB}_{2}-\mathrm{Cu}$ composite as an EDM electrode. J. Mater. Process. Technol. 2007, 183, 122-126. [CrossRef]

24. Tsai, H.C.; Yan, B.H.; Huang, F.Y. EDM performance of $\mathrm{Cr} / \mathrm{Cu}$-based composite electrodes. Int. J. Mach. Tools Manuf. 2003, 43, 245-252. [CrossRef]

25. Grisharin, A.O.; Ogleznev, N.D.; Muratov, K.R.; Ablyaz, T.R.; Bains, P.S.; Sidhu, S.S. Investigation of the machinability of composite materials electrode-tools while EDM. Conf. Ser. Mater. Sci. Eng. 2019, 510, 012006. [CrossRef]

26. Teng, Y.L.; Li, L.; Zhang, W.; Wang, N.; Feng, C.C.; Ren, J.H. Machining characteristics of PCD by EDM with Cu-Ni composite electrode. Mater. Manuf. Process. 2020, 35, 442-448. [CrossRef]

27. Quarto, M.; Bissacco, G.; D’Urso, G. Machinability and energy efficiency in micro-EDM milling of zirconium boride reinforced with silicon carbide fibers. Materials 2019, 12, 3920. [CrossRef]

28. D’Urso, G.; Giardini, C.; Lorenzi, S.; Quarto, M.; Sciti, D.; Silvestroni, L. Micro-EDM milling of zirconium carbide ceramics. Precis. Eng. 2020, 65, 156-163. [CrossRef]

29. Wang, Z.L.; Fang, Y.; Wu, P.N.; Zhao, W.S.; Cheng, K. Surface modification process by electric discharge machining with a Ti powder green compact electrode. J. Mater. Process. Technol. 2002, 129, 139-142. [CrossRef]

30. Malayath, G.; Sidpara, A.M.; Deb, S. Fabrication of micro-end mill tool by EDM and its performance evaluation. Mach. Sci. Technol. 2019, 24, 169-194. [CrossRef]

31. Pratap, T.; Patra, K. Mechanical micro-texturing of Ti-6Al-4V surfaces for improved wettability and bio-tribological performances. Surf. Coat. Technol. 2018, 349, 71-81. [CrossRef]

32. Azevedo, A.F.; Corat, E.J.; Ferreira, N.G.; Trava-Airoldi, V.J. Wettability and corrosion tests of diamond films grown on Ti6Al4V alloy. Surf. Coat. Technol. 2005, 194, 271-275. [CrossRef]

33. Kliuev, M.; Florio, K.; Akbari, M.; Wegener, K. Influence of energy fraction in EDM drilling of inconel 718 by statistical analysis and finite element crater-modeling. J. Manuf. Process. 2019, 40, 84-93. [CrossRef]

34. Kumar, R.; Roy, S.; Gunjan, P.; Sahoo, A.; Sarkar, D.D.; Das, R.K. Analysis of MRR and surface roughness in machining Ti-6Al-4V ELI titanium alloy using EDM process. Procedia Manuf. 2018, 20, 358-364. [CrossRef]

35. Singh, G.; Sidhu, S.S.; Bains, P.S.; Bhui, A.S. Surface evaluation of ED machined 316L stainless steel in $\mathrm{TiO}_{2}$ nano-powder mixed dielectric medium. Mater. Today Proc. 2019, 18, 1297-1303. [CrossRef]

36. Devgan, S.; Sidhu, S.S. Evolution of surface modification trends in bone related biomaterials: A review. Mater. Chem. Phys. 2019, 223, 68-78. [CrossRef]

37. Harcuba, P.; Bacakova, L.; Strasky, J.; Bacakova, M.; Novotna, K.; Janecek, M. Surface treatment by electric discharge machining of Ti-6Al-4V alloy for potential application in orthopaedics. J. Mech. Behav. Biomed. Mater. 2012, 7, 96-105. [CrossRef]

38. Mahajan, A.; Sidhu, S.S. Surface modification of metallic biomaterials for enhanced functionality: A review. Mater. Technol. 2018, 33, 93-105. [CrossRef]

39. Cogun, C.; Esen, Z.; Genc, A.; Cogun, F.; Akturk, N. Effect of powder metallurgy Cu-B ${ }_{4}$ C electrodes on workpiece surface characteristics and machining performance of electric discharge machining. Proc. IMechE Part B J. Eng. Manuf. 2016, 230, 2190-2203. [CrossRef] 
40. Ji, R.; Liu, Y.; Diao, R.; Xu, C.; Li, X.; Cai, B.; Zhang, Y. Influence of electrical resistivity and machining parameters on electrical discharge machining performance of engineering ceramics. PLOS ONE 2014, 9, e110775. [CrossRef]

41. Devgan, S.; Sidhu, S.S. Enhancing tribological performance of $\beta$-titanium alloy using electrical discharge process. Surf. Innov. 2019, 8, 115-126. [CrossRef]

42. Hesketh, J.; Ward, M.; Dowson, D.; Neville, A. The composition of tribofilms produced on metal-on-metal hip bearings. Biomaterials 2014, 35, 2113-2119. [CrossRef] [PubMed]

43. Singh, G.; Sidhu, S.S.; Bains, P.S.; Singh, M.; Bhui, A.S. On surface modification of Ti alloy by electro discharge coating using hydroxyapatite powder mixed dielectric with graphite tool. J. Bio Tribo Corros. 2020, 6, 91. [CrossRef]

44. Buyukgoze-Dindar, M.; Tekbas-Atay, M. The effect of toothbrush abrasion on wear and surface roughness of direct and indirect composite laminate veneer restorations. Surf. Topogr. Metrol. Prop. 2020, 8, 035007. [CrossRef]

45. Chen, S.L.; Lin, M.H.; Huang, G.X.; Wang, C.C. Research of the recast layer on implant surface modified by micro-current electrical discharge machining using deionized water mixed with titanium powder as dielectric solvent. Appl. Surf. Sci. 2017, 311, 47-53. [CrossRef]

46. Gostimirovic, M.; Kovac, P.; Sekulic, M.; Skoric, B. Influence of discharge energy on machining characteristics in EDM. J. Mech. Sci. Technol. 2012, 26, 173-179. [CrossRef]

47. Sauli, Z.; Retnasamy, V.; Yeow, A.K.T.; Chui, G.S.; Anwar, K.; Abdullah, N. Surface roughness and wettability correlation on etched platinum using reactive ion ecthing. Appl. Mech. Mater. 2014, 487, 263-266. [CrossRef]

48. Bharathidasan, T.; Kumar, S.V.; Bobji, M.S.; Chakradhar, R.P.S.; Basu, B.J. Effect of wettability and surface roughness on ice-adhesion strength of hydrophilic, hydrophobic and superhydrophobic surfaces. Appl. Surf. Sci. 2014, 314, 241-250. [CrossRef]

49. Yang, S.; Xia, Q.; Zhu, L.; Xue, J.; Wang, Q.; Chen, Q.M. Research on the icephobic properties of fluoropolymer-based materials. Appl. Surf. Sci. 2011, 257, 4956-4962. [CrossRef]

50. Kumar, S.S.; Hiremath, S.S. Effect of surface roughness and surface topography on wettability of machined biomaterials using flexible viscoelastic polymer abrasive media. Surf. Topogr. Metrol. Prop. 2019, 7, 015004. [CrossRef]

51. Puckett, S.D.; Lee, P.P.; Ciombor, D.M.; Aaron, R.K.; Webster, T.J. Nanotextured titanium surfaces for enhancing skin growth on transcutaneous osseointegrated devices. Acta Biomater. 2010, 6, 2352-2362. [CrossRef]

(C) 2020 by the authors. Licensee MDPI, Basel, Switzerland. This article is an open access article distributed under the terms and conditions of the Creative Commons Attribution (CC BY) license (http://creativecommons.org/licenses/by/4.0/). 